Rok XIV (2019) | 2 (28) | s. 57-69

https://doi.org/10.12797/LV.14.2019.28.04

Barbara Hlibowicka-Węglarz @

Uniwersytet Marii Curie-Skłodowskiej, Lublin

hlibowickaweglarzb@gmail.com

\title{
STRUKTURA KREOLSKICH FORM WERBALNYCH
}

Słowa klucze: język kreolski, kategoria gramatyczna, aspekt, czas, tryb Keywords: creole language, grammatical category, aspect, tense, mood

\section{Wprowadzenie}

Języki kreolskie to języki mieszane, ukształtowane w specyficznych warunkach społeczno-historycznych ${ }^{1}$ i charakteryzujące się pewnymi stałymi cechami strukturalnymi². W porównaniu $\mathrm{z}$ innymi językami naturalnymi stanowią odrębny typ języków. Jak uważa większość badaczy, u podstaw odrębności kreoli leży przede wszystkim ich krótki okres formowania ${ }^{3}$, który nie pozwolił na rozwinięcie bardziej złożonych struktur gramatycznych, tak jak to miało miejsce w przypadku innych języków naturalnych powstałych w procesie długotrwałej ewolucji ${ }^{4}$.

1 Na temat warunków sprzyjających powstawaniu kreoli, ich pochodzenia oraz cech wyróżniających zob. Hlibowicka-Węglarz 2013, 2018.

2 Derek Bickerton $(1981,1984)$ analizował kreole uformowane na bazie języka angielskiego i zaproponował 12 cech strukturalnych, które, jego zdaniem, są wspólne wszystkim językom kreolskim, a jednocześnie odróżniają je od innych języków naturalnych.

3 Języki kreolskie kształtują się w tzw. „sytuacji kryzysu językowego” w okresie nawet jednego stulecia (Pereira 2006).

4 Na temat odrębności typologicznej kreoli oraz ich cech charakterystycznych zob. Hagemeijer, Alexandre 2012. 
Celem niniejszej pracy jest opis cech morfosyntaktycznych systemu czasownika kreolskiego wraz z zasadami jego funkcjonowania. Najwięcej uwagi poświęcimy analizie środków wyrazu kategorii gramatycznych czasu, trybu i aspektu, czyli tzw. systemowi TMA ${ }^{5}$, który budzi największe zainteresowanie wielu autorów ze względu na oryginalność zespolenia morfemów leksykalnych z morfemami gramatycznymi, z których każdy pełni zazwyczaj tylko jedną funkcję gramatyczną.

Biorąc pod uwagę różnorodność form werbalnych, którymi dysponują różne języki kreolskie, zaprezentujemy jedynie podstawowe mechanizmy ich tworzenia i funkcjonowania. Cytowane przez nas przykłady pochodzą z języka santiaguense, najstarszej odmiany kreola z archipelagu Wysp Zielonego Przylądka (port. Cabo Verde $)^{6}$, ukształtowanego na bazie leksykalnej języka portugalskiego. Podobnie jak inne kreole z regionu tzw. Górnej Gwinei ${ }^{7}$, uformował się on w XVI w., w wyniku kontaktu języka portugalskiego $\mathrm{z}$ rdzennymi językami afrykańskimi z rodziny niger-kongo.

\section{Podstawowe formy werbalne}

W odróżnieniu od języka portugalskiego, dysponującego mnogością form fleksyjnych, kreolski czasownik w języku santiaguense nie ma fleksji. Podstawowa forma czasownika jest niezmienna w odniesieniu do wszystkich osób liczby pojedynczej i mnogiej, co potwierdzają przykłady dwóch czasowników: kume (port. comer, pol. jeść) oraz konxi (port. conhecer, pol. znać):

\begin{tabular}{|cll|}
\hline Kategoria osoby i liczby & kume & konxi \\
\hline $1 \mathrm{sg}$ & N kume & N konxi \\
$2 \mathrm{sg}$ & bu kume & bu konxi \\
$3 \mathrm{sg}$ & el kume & el konxi \\
$1 \mathrm{pl}$ & nu kume & nu konxi \\
\hline $2 \mathrm{pl}$ & nhos kume & nhos konxi \\
$3 \mathrm{pl}$ & es kume & es konxi \\
\hline
\end{tabular}

5 System TMA - system wykładników czasu ( $\mathrm{T}$ - tense), trybu $(\mathrm{M}$ - mood) i aspektu (A - aspect). Analizując system TMA w angielskich językach kreolskich, Bickerton (1981) proponuje przypisać następujące cechy poszczególnym kategoriom gramatycznym: [£duratywność] dla kategorii aspektu, cechę [ \pm uprzedniość] dla kategorii czasu oraz cechę [ \pm nierzeczywistość] dla kategorii trybu.

6 Santiaguense to najstarsza odmiana kreola caboverdiano, uformowana na wyspie Santiago, pierwszej zaludnianej wyspie archipelagu.

7 Do grupy tej należą również: język kreolski z Gwinei Bissau (guineense) oraz kreol z regionu Casamance w Senegalu. 
Wszystkie osoby liczby pojedynczej i mnogiej są reprezentowane przez jedną formę werbalną, zawsze poprzedzoną zaimkiem osobowym dla wskazania agensa wykonywanej czynności. Jak wskazują cytowane powyżej przykłady, kreol santiaguense dysponuje trzema zaimkami liczby pojedynczej $(N, b u, e l)$ oraz trzema liczby mnogiej ( $n u, n h o s, e s)$. Obligatoryjne użycie zaimka osobowego przed formą werbalną jest cechą wspólną wszystkich kreoli ze względu na brak w tych językach form fleksyjnych.

Dla porównania, w języku portugalskim (podobnie jak w wielu innych) wszystkie kategorie gramatyczne czasownika (osoba, liczba, czas, aspekt, tryb i strona) zakodowane są w afiksach fleksyjnych - końcówkach form werbalnych. W odróżnieniu od kreoli morfemy gramatyczne są w tym języku ściślej zespolone z morfemami leksykalnymi i kumulują kilka funkcji gramatycznych (port. como, comes, come, comemos, comeis, comem). Dla przykładu, w morfemie gramatycznym portugalskiej formy comem ('jedzą) zakodowane są informacje na temat wszystkich werbalnych kategorii gramatycznych: 3. os., lmn., cz. ter., aspekt ndk., tryb oznajm., strona czynna. Ze względu na możliwość jednoznacznej interpretacji każdej portugalskiej formy werbalnej użycie zaimka osobowego w funkcji podmiotu jest fakultatywne. Kreolskiej formie es kume odpowiada portugalska forma comem, która nie wymaga określenia agensa wykonywanej czynności, gdyż informacja na ten temat zawarta jest w końcówce czasownika.

\section{Prymarna funkcja kategorii aspektu}

Następnym zagadnieniem, na które powinniśmy zwrócić uwagę w naszych rozważaniach, jest prymarna funkcja kategorii aspektu w systemie czasownika kreolskiego, a priori różnicująca wszystkie formy werbalne. Kategoria czasu odgrywa w tym systemie rolę drugorzędną, natomiast trzeciorzędne znaczenie przypisuje się kategorii trybu. W opinii badaczy (Veiga 1995; Quint 2005) ta fundamentalna rola aspektu w kreolskim systemie werbalnym jest również jedną z najważniejszych różnic między językami kreolskimi a innymi językami, które w swoich systemach przywiązują większą wagę do kategorii czasu i trybu.

Zwróćmy uwagę, że w paradygmacie werbalnych form portugalskich kategoria czasu odgrywa rolę najważniejszą, sytuując dane wydarzenie na jego osi względem momentu mówienia (przeszłość, teraźniejszość, przyszłość). Kategoria trybu, definiująca postawę mówiącego względem wypowiadanej treści (rzeczywistość, nierzeczywistość), odgrywa w tym języku rolę drugorzędną. Natomiast ze względu na fakt, że aspekt reprezentowany jest głównie przez wykładniki czasów gramatycznych ${ }^{8}$,

8 Omówienie gramatycznych i leksykalnych wykładników aspektu w portugalskim zob. Hlibowicka-Węglarz 1998. 
czas i aspekt tworzą w języku portugalskim kompleks ściśle ze sobą powiązanych kategorii gramatycznych.

Aby wyjaśnić, na czym polega prymarna rola aspektu w kreolach, przeanalizujmy znaczenie dwóch cytowanych powyżej form: el konxi oraz el kume. Pierwsza z nich (el konxi) odnosi się do czasu teraźniejszego (port. conhece - pol. zna), druga (el kume) do czasu przeszłego (port. comeu - pol. zjadł). Jak to zatem możliwe, że dwa czasowniki, które zostały zaprezentowane w ten sam sposób, sytuują wydarzenia, do których się odnoszą, w różnych czasach gramatycznych?

Tu należy wyjaśnić, że w zdaniu kreolskim punktem odniesienia jest sama czynność, a nie moment mówienia (tzw. To), jak to się dzieje w wielu językach naturalnych (również w portugalskim). Couto (1996: 39) tłumaczy, że „w językach kreolskich każda czynność może być zrelacjonowana dopiero po tym, jak się wydarzy” 9 Dlatego też każdy czasownik w swej podstawowej formie wyraża aspekt dokonany, czyli czynność całkowicie zakończoną w przeszłości. Zasada ta odnosi się do form podstawowych, które występują bez żadnego wykładnika gramatycznego. Są one nienacechowane, tak jak czasowniki kume i konxi.

Biorąc pod uwagę powyższą zasadę, spróbujmy dokonać interpretacji semantycznej formy el konxi, wiedząc, że jest to forma perfektywna. Skoro „jakiś on poznał kogoś” implikuje, że (jeśli nie ma on problemów z pamięcią) obecnie też go $z n a$, to el konxi odnosi się do czynności w czasie teraźniejszym, która staje się formą niedokonaną. W przypadku formy el kume podobna interpretacja doprowadza do innego wniosku: skoro „jakiś on coś zjadl”, a czynność jest już zakończona, to w chwili obecnej on już nie je. W rezultacie forma ta odnosi się do przeszłości, jest dokonana.

\section{Czasowniki mocne i słabe}

Analiza dwóch czasowników regularnych z języka santiaguense tłumaczy, jak należy rozumieć prymarną rolę aspektu w kreolskim systemie werbalnym: wszystkie nienacechowane formy regularnych czasowników interpretowane są zawsze jako dokonane.

Obecnie zwróćmy uwagę na różnice semantyczne między czasownikami kume i konxi. Zauważmy, że podczas gdy kume jest czasownikiem wyrażającym czynność, konxi jest czasownikiem stanowym. Ze względu na rodzaj czynności wyrażany przez formę werbalną badacze wyróżniają w kreolach tzw. czasowniki mocne i słabe. Czasowniki mocne to czasowniki stanowe, oznaczające sytuacje statyczne, natomiast czasowniki słabe, czyli dynamiczne, oznaczają czynności. Pamiętamy, że czasownik stanowy konxi w swej podstawowej formie tłumaczony był przez formy

9 „Toda a acção só pode ser narrada depois de ocorrida” (Couto 1996: 39). 
czasu teraźniejszego, podczas gdy czasownik czynności kume oznaczał czynność zakończoną w przeszłości.

Reasumując, podstawowe formy werbalne czasowników mocnych (bez wykładników kategorii gramatycznych) wyrażają aspekt niedokonany i są tłumaczone przez formy czasu teraźniejszego, natomiast formy czasowników słabych wyrażają aspekt dokonany i interpretowane są jako czynności przeszłe. Regularne czasowniki czynnościowe są w językach kreolskich znacznie liczniejsze aniżeli czasowniki stanowe.

\section{Wykładniki kategorii gramatycznych}

Skoro forma dokonana słabego czasownika kume odnosi się do przeszłości, zastanówmy się, jakimi środkami wyrazu dysponuje język santiaguense dla wyrażania czasu teraźniejszego. W jaki sposób możemy przekształcić dokonaną formę kume, aby oznaczała czynność niedokonaną? Okazuje się, że w tym celu badany kreol posługuje się wykładnikiem $t a^{10}$, który zawsze poprzedza formę podstawową $(N$ ta kume - ‘jem’). Warto zauważyć, że obecność wykładnika ta w strukturze formy werbalnej pozwala również na szybkie odróżnienie form niedokonanych tzw. słabych czasowników regularnych (z wykładnikiem $t a$ ) od form dokonanych (bez wykładnika $t a)$.

Dla wyrażania różnych wartości aspektowych, czasowych i modalnych santiaguense posługuje się kilkoma strategiami. Formie nienacechowanej (kume) mogą towarzyszyć nawet trzy morfemy poprzedzające formę podstawową: $t a$, sa ta oraz al. Partykuła ta jest wykładnikiem aspektu niedokonanego, kombinacja sa ta wyraża aspekt niedokonany i dodatkowo wartość duratywną, zaś partykuła al jest wykładnikiem modalnym. Jeśli dla wyrażenia konfiguracji różnych wartości aspektowych i modalnych zachodzi potrzeba użycia kilku z nich, występują one zawsze w tej samej kolejności: $(a l)^{11}(s a t a)^{12}(t a)+$ podstawowa forma czasownika.

Poza wymienionymi wykładnikami występującymi zawsze w pozycji prewerbalnej santiaguense dysponuje dodatkowo trzema formami syntetycznymi z wykładnikami: -ba (kumeba), -du (kumedu), -da (kumeda). Forma z -ba wyraża uprzedniość w stosunku do form nienacechowanych, wykładnik - $d u$ wyraża formę pasywną, natomiast $-d a$, będący połączeniem wykładnika $-d u$ z $-b a$, kumuluje obie wspomniane wartości, a mianowicie: uprzedniość oraz pasywność.

10 Wykładnik ta pochodzi od portugalskiej formy está (czasownik: estar - 'być, znajdować się w danym momencie').

11 Wykładnik al nigdy nie występuje z wykładnikiem $t a$. Pojawia się w sekwencji al sa ta dla połączenia wartości modalnych z cechą [+duratywność].

12 Wykładnik $s a$ występuje zawsze z wykładnikiem $t a$, gdyż obie formy są wykładnikami aspektu niedokonanego. Duratywność implikuje zawsze niedokonaność (Lang 2018). 
Wykładniki, jakimi dysponuje santiaguense, zawierają istotne dla zdefiniowania każdej formy informacje na temat wszystkich werbalnych kategorii gramatycznych. Opozycja form ta kume vs kume, podobnie jak sa ta kume vs kume jest opozycją aspektową, jednocześnie najważniejszą opozycją w całym systemie. Opozycja pomiędzy kumeba vs kume bazuje na kategorii czasu rozumianego jako czas względ$\mathrm{ny}^{13}$, opozycja form al kume vs kume jest opozycją modalną, natomiast opozycja kumedu vs kume odnosi się do kategorii strony. Opozycja form kumeda vs kume kumuluje wartości odnoszące się jednocześnie do dwóch kategorii gramatycznych: strony i czasu. Cały ten system bazuje zatem na opozycjach form morfologicznie nacechowanych $\mathrm{z}$ formami nienacechowanymi $\mathrm{w}$ odniesieniu do poszczególnych kategorii gramatycznych.

Na kilku przykładach przedstawimy funkcjonowanie tego systemu, przypisując różnym formom języka santiaguense ich interpretację semantyczną: $N$ kanta (śpiewałem), $N$ ta kanta ('́piewam), $N$ sa ta kanta (jestem w trakcie śpiewania), $N$ ta kantadu (śpiewa się), $N$ ta kantaba (śpiewali) itd.

Dotychczasowe uwagi odnosiły się do tzw. czasowników czynnościowych (kume, kanta), czyli czasowników słabych. Dla porównania warto uzupełnić nasz opis o kilka obserwacji na temat funkcjonowania tzw. czasowników mocnych, czyli czasowników stanowych (np. konxi). Jak wiadomo, czasowniki te w swej podstawowej formie odnoszą się do czasu teraźniejszego (konxi 'znam'). Jürgen Lang (2018) zestawia przykłady regularnych czasowników czynności i stanowych, aby wskazać na różnice $\mathrm{w}$ ich interpretacji semantycznej. W grupie czasowników czynności wspomniany autor cytuje:

El nkontra Djuzé (encontrou o José - spotkał Józefa) - forma nienacechowana, dokonana.

El ta nkontra Djuzé (El encontra o José - spotyka Józefa) - forma nacechowana, niedokonana.

W pierwszym zdaniu mocny czasownik nkontra (spotykać) ujmuje czynność jako dokonaną. Wykładnik ta poprzedzający czasownik nkontra w drugim zdaniu zmienia interpretację semantyczną tej formy na niedokonaną. W grupie czasowników stanowych forma podstawowa odnosi się do teraźniejszości:

El txoma Djuzé (chama-se José - nazywa się Józef) - forma nienacechowana, niedokonana.

13 Język santiaguense nie posiada czasów gramatycznych. Dysponuje jedynie wykładnikiem -ba, który wskazuje na czynność wcześniejszą w stosunku do czynności wyrażonej przez formę nienacechowaną. 
Niektóre wykładniki w systemie TMA mogą być polifunkcyjne, tak jak np. wykładnik ta, który w połączeniu z czasownikiem stanowym ${ }^{14}$ txoma (nazywać się) może odnosić się do czasu przyszłego (El ta txoma - będzie się nazywać).

Wykładnik - $b a \mathrm{w}$ formie syntetycznej z czasownikiem mocnym wyraża prosty czas przeszły (El txomaba Djuzé - chamava-se José - nazywał się Józef), a nie czas zaprzeszły jak w wypadku czasowników słabych (El nkontraba Djuzé - tinha encontrado o José - spotkał był wcześniej Józefa). Należy tu pamiętać, że wykładnik -ba wyraża uprzedniość w stosunku do formy podstawowej. Skoro więc forma czasownika mocnego txoma znaczy 'nazywa się, to oznaczająca uprzedniość forma txoma$\underline{b a}$ znaczy 'nazywał się'. Skoro czasownik słaby nkontra znaczy 'spotkał', to forma nkontraba z wykładnikiem uprzedniości znaczy 'spotkał wcześniej’.

Sekwencja sa ta, zarówno z czasownikami stanowymi, jak i czynności, może wyrażać trwanie w momencie wypowiedzenia wraz z informacją, iż będzie ona kontynuowana w przyszłości, tak jak w zdaniu:

El sa ta ser nos prezidenti - Ele e actualmente o nosso presidente - on jest teraz naszym prezydentem + będzie nim w przyszłości.

Należy na koniec zwrócić uwagę, że struktura kreolskich form werbalnych może zależeć również od kontekstu, który zezwala na redukcję niektórych wykładników ${ }^{15}$. Dlatego też warto podkreślić, że przedstawione przez nas zasady funkcjonowania wykładników poszczególnych kategorii gramatycznych w kreolu z Santiago stanowią podstawę całego mechanizmu, który nie jest jednak wolny od wielu odstępstw. Problematyka wpływu kontekstu na tworzenie kreolskich form werbalnych jest jednak tak bardzo złożona, że mogłaby stanowić temat oddzielnej pracy.

Reasumując, aby „odszyfrować” pełne znaczenie poszczególnych form werbalnych, potrzebna jest wiedza nie tylko o wartościach semantycznych wszystkich wykładników systemu TMA, lecz także o całym złożonym mechanizmie ich funkcjonowania.

\section{System form werbalnych w języku santiaguense}

Uwagi dotyczące funkcjonowania wykładników kategorii gramatycznych w syntagmie werbalnej języków kreolskich potwierdzają oryginalność struktur kreolskich w stosunku do struktur języka superstratu. Badania wielu kreoli dowodzą, że

14 Wykładnik ten może również podkreślać wartość habitualną czynności wyrażonej przez czasownik stanowy, np. El ta sta senpri na kasa - Ele costuma estar sempre na casa - ma zwyczaj zawsze być w domu.

15 Gdy kontekst wyklucza inną interpretację danej formy, redukcji może ulec nawet wykładnik imperfektywności $t a$. 
powszechnie stosowaną strategią dla wyrażania kategorii werbalnych we wszystkich tych językach jest posługiwanie się oddzielnymi morfemami, które mają zakodowane swoiste wartości aspektowe, czasowe i modalne.

Wśród współczesnych autorów prac na temat struktur języka santiaguense należy wymienić niemieckiego autora J. Langa (ibid.), a także pochodzącego z Wysp Zielonego Przylądka Manuela Veigę $(1995,2002)$. W dalszej części postaramy się przedstawić, w jaki sposób wspomniani kreoliści prezentują rezultaty swych badań na temat systemu form werbalnych w języku santiaguense.

Lang (2018: 137) proponuje zestawienie form najliczniej reprezentowanych w tym języku czasowników czynności na przykładzie regularnego czasownika kanta (port. cantar 'śpiewać'):

\begin{tabular}{llllll} 
& & [anterior] & $\begin{array}{c}\text { [anterior] }+ \\
\text { [passivum] }\end{array}$ & [passivum] & [eventual] \\
\hline & El kanta & El kantaba & Kantada & Kantadu & $(-)$ \\
Imperfectivum & El ta kanta & El ta kantaba & Ta kantada & Ta kantadu & $(-)$ \\
$\begin{array}{l}\text { Imperfectivum } \\
\text { Durativum }\end{array}$ & El sa ta kanta & El sa ta kantaba & Sa ta kantada & Sa ta kantadu & $(-)$ \\
$(-)$ & El al kanta & El al kantaba & (Al kantada) & Al kantadu & $(+)$ \\
Durativum & El al sa ta & El al sa ta & Al sa ta kantada & $\begin{array}{l}\text { Al sa ta kan- } \\
\text { tadu }\end{array}$ & $(+)$
\end{tabular}

Lang (ibid.) zestawia formy werbalne kreola $z$ Santiago, dzieli je na formy dokonane i niedokonane i biorąc pod uwagę obecność różnych wykładników w każdej $\mathrm{z}$ tych form, przypisuje im określone miejsce w całym systemie. Klasyfikacja form werbalnych zaprezentowana przez autora potwierdza opisane przez nas zasady tworzenia form werbalnych.

Na uwagę zasługuje jednak brak zaimka osobowego poprzedzającego formę werbalną w formach pasywnych, czyli formach syntetycznych z wykładnikami - $d u$ oraz -da. Dzieje się tak, gdyż w santiaguense, ze względu na brak możliwości zwiększenia liczby implikowanych na płaszczyźnie semantycznej argumentów, formy z wykładnikiem pasywnym eliminują argument, który w formach aktywnych pełniłby funkcję podmiotu. Na przykład forma el kanta (zaśpiewał) w stosunku do kantadu (jest zaśpiewany/a) traci formę osobową i staje się formą bezosobową (zaśpiewało się), uważaną za szczególną odmianę passivum. W celu wyrażenia agensa wykonywanej czynności w formach pasywnych badany kreol dysponuje konstrukcjami peryfrastycznymi.

Konkludując, dla wyrażania różnych wartości aspektowych, czasowych i modalnych santiaguense posługuje się trzema wykładnikami, w pozycji prewerbalnej występującymi zawsze $\mathrm{w}$ ściśle określonym porządku w stosunku do czasownika, oraz trzema morfemami gramatycznymi tworzącymi z nienacechowaną formą werbal- 
ną formy syntetyczne. Wartość semantyczna tak skonstruowanej formy jest zawsze konfiguracją wartości wyrażanych przez poszczególne wykładniki wchodzące w jej skład.

W odmienny sposób opisuje system form werbalnych w kreolu z wyspy Santiago M. Veiga (1995, 2002), dzieląc je na formy niedokonane (forma não realizada) i dokonane (forma realizada). Wśród form niedokonanych wspomniany autor rozróżnia dodatkowo formy progresywne (progressivo), habitualne (habitual), nieokreślone (indefinido) oraz przypuszczające (eventual). Veiga (2002: 97-104) wymienia następujące formy niedokonane regularnego czasownika kume (jeść):

N ta kume - habitual actuallfuturo (como, comerei - jem, będę jeść).

N sa ta kume - progressiva actual (estou a comer - jestem w trakcie jedzenia).

$N$ al kume - eventual prospectiva (hei-de comer - mam do zjedzenia).

N ta kumeba - anterior passada (comia - jadałem).

N al kumeba - eventual no passado (deveria comer - powinienem jeść).

N ta kumedu - indefinida (come-se - je się, jada się).

N sa ta kumedu - indefinida progressiva (está-se a comer - jest się w trakcie jedzenia).

$N$ al kumedu - eventual indefinida (deve-se estar a comer - powinno się jeść).

$N$ al sa ta kumedu - eventual indefinida progressiva (deve-se estar a comer - powinno się być w trakcie jedzenia).

$N$ al kumeda - eventual indefinida no passado (talvez a gente comesse - być może się jadło).

$\mathrm{N}$ al sa ta kumeda - eventual progressiva no passado (devia-se estar a comer - powinno się było jeść).

Interpretacja semantyczna wszystkich wymienionych form uzależniona jest od kombinacji występujących w danej syntagmie werbalnej wykładników gramatycznych. Dla łatwiejszego zrozumienia omawianych przykładów autor dołączył odpowiadające im formy $\mathrm{w}$ języku portugalskim, natomiast my uzupełniliśmy je odpowiednikami polskimi. Zwróćmy uwagę, że układ poszczególnych wykładników jest zawsze taki sam: wykładniki kategorii aspektu występują jako luźne morfemy bezpośrednio przed formą nienacechowaną, wykładnik kategorii trybu (al) przed wykładnikami kategorii aspektu. Wykładnik kategorii czasu -ba łączy się z formą nienacechowaną, tworząc formy syntetyczne, podobnie jak omówione już wykładniki $-d u$ i $-d a$. 
Veiga (2002) w podobny sposób opisuje formy dokonane:

N kume - realizada, passado remoto ${ }^{16}$ (comi - zjadłem).

dja $N$ kume dja - realizada, presente recente ${ }^{17}$ (acabei de comer - dopiero co zjadłem).

dja $N$ kumeba dja - realizada no passado anterior recente (tinha comido - zjadłem wcześniej, uprzednio).

N kumedu - realizada actual indefinida (a gente comeu - zjadło się).

$N$ kumedu dja - realizada indefinida recente (tem-se já comido - dopiero co się zjadło, już się nie je).

$N$ kumeda - realizada indefinida no passado anterior (tinha-se comido - jadło się wcześniej).

dja $N$ kumeda dja - realizada indefinida no pasado anterior conclusivo (tinha-se acabado de comer - skończyło się wcześniej jeść).

Jak wskazują przykłady, dla wyrażania form dokonanych język santiaguense posługuje się wykładnikiem dja (port. já, pol. już), który występuje jedynie z formą nienacechowaną lub z syntetycznymi formami z $-b a$, $-d a$ i $-d u$. Przypomnijmy, że czasownik regularny kume należy do grupy czasowników słabych i dlatego też, gdy występuje bez dodatkowego wykładnika, odnosi się do przeszłości (kume - 'zjadłem').

\section{Konfiguracje wartości aspektowych, temporalnych i modalnych}

Porównując prezentacje systemu form werbalnych autorstwa dwóch współczesnych badaczy języka santiaguense (Lang 2018; Veiga 1995, 2002), należy zwrócić uwagę na kilka różnic pomiędzy nimi. Po pierwsze, podczas gdy Lang daje dokładny opis funkcjonowania całego systemu, prezentując wszelkie współzależności pomiędzy poszczególnymi wykładnikami w formie tabeli, Veiga (2002) prezentuje wszystkie formy, definiując każdą z nich poprzez przypisanie jej odrębnej nazwy (np. forma progressiva actual). Tak więc sam zaproponowany przez obu autorów sposób opisu jest odmienny. Po drugie, obydwaj autorzy posługują się w swych opisach innymi pojęciami. Wśród form niedokonanych Veiga $(1995,2002)$ wyróżnia m.in. formy progresywne i habitualne, podczas gdy Lang nie robi tego rozróżnienia i mówi jedynie o formach duratywnych, gdyż zarówno formy progresywne, jak i habitualne są przecież duratywne ${ }^{18}$. Jeszcze inną różnicą o charakterze terminologicznym jest

16 Czynność dokonana w dalszej przeszłości.

17 Czynność dokonana w bliskiej przeszłości.

18 Lang (ibid.) przyznaje, że większość form, które on nazywa duratywnymi, jest progresywna. 
rozróżnienie pomiędzy formami pasywnymi (Lang) i nieokreślonymi (Veiga). Pamiętamy, że pasywne formy werbalne z wykładnikami - $d u$ i $-d a$ w języku santiaguense stają się formami bezosobowymi i zapewne stąd pochodzi różnica w używanych pojęciach u obu autorów. Porównanie obu opisów pozwala na stwierdzenie, że różnice pomiędzy nimi polegają na posługiwaniu się przez autorów kilkoma innymi pojęciami, a także na odmiennym sposobie samego opisu.

Grupując analizowane przez nas przykłady, proponujemy jeszcze inną próbę opisu, wychodząc od nienacechowanej morfologicznie formy czasownika regularnego i uzupełniając ją kolejno o poszczególne wykładniki kategorii gramatycznych, respektując ich ściśle określone miejsce w syntagmie werbalnej. Tabela poniżej przedstawia tak zestawione formy niedokonane w kreolu z wyspy Santiago:

\begin{tabular}{|c|c|c|c|c|c|c|}
\hline \multirow{2}{*}{$\begin{array}{c}(\mathrm{M}) \\
{[+ \text { eventual }]}\end{array}$} & \multicolumn{2}{|c|}{ (A) Imperfectivum } & \multirow[b]{2}{*}{ V } & \multirow{2}{*}{$\begin{array}{c}(\mathrm{T}) \\
{[\text { +anterior] }}\end{array}$} & \multirow[b]{2}{*}{$\begin{array}{c}\text { [+indefini- } \\
\text { do }]\end{array}$} & \multirow{2}{*}{$\begin{array}{c}{[+ \text { indefini- }} \\
\text { do }]+ \\
{[+ \text { anterior }]}\end{array}$} \\
\hline & $\begin{array}{c}{[+ \text { progres- }} \\
\text { sivo }]\end{array}$ & [+habitual] & & & & \\
\hline & & + & N ta kume & & & \\
\hline & + & & $\begin{array}{l}\text { Nsa ta } \\
\text { kume }\end{array}$ & & & \\
\hline \multirow[t]{2}{*}{+} & & & N al kume & & & \\
\hline & & + & $\begin{array}{l}\text { Nta } \\
\text { kumeba }\end{array}$ & + & & \\
\hline+ & & & $\begin{array}{l}\text { Nal } \\
\text { kumeba }\end{array}$ & + & & \\
\hline \multirow[t]{3}{*}{+} & & & $\begin{array}{l}\text { Nal sa ta } \\
\text { kumeba }\end{array}$ & + & & \\
\hline & & + & $\begin{array}{l}\text { N ta } \\
\text { kumedu }\end{array}$ & & + & \\
\hline & + & & $\begin{array}{l}\text { Nsa ta } \\
\text { kumedu }\end{array}$ & & + & \\
\hline+ & & & $\begin{array}{l}\text { Nal } \\
\text { kumedu }\end{array}$ & & + & \\
\hline+ & + & & $\begin{array}{l}N \text { al sa } \boldsymbol{t a} \\
\text { kumed } \boldsymbol{u}\end{array}$ & & + & \\
\hline+ & & & $\begin{array}{l}\text { Nal } \\
\text { kumeda }\end{array}$ & & & + \\
\hline+ & + & & $\begin{array}{l}\text { Nal sa } \boldsymbol{t a} \\
\text { kumeda }\end{array}$ & & & + \\
\hline
\end{tabular}


W analogiczny sposób proponujemy zestawić formy dokonane:

\begin{tabular}{|c|c|c|c|c|c|}
\hline [+anterior] & $\begin{array}{l}{[+ \text { Praeteri- }} \\
\text { tum remoto] }\end{array}$ & $\begin{array}{l}{[+ \text { Praeteri- }} \\
\text { tum recente] }\end{array}$ & V & [+indefinido] & $\begin{array}{c}\text { [+indefini- } \\
\text { do }]+ \\
{[+ \text { anterior }]}\end{array}$ \\
\hline & + & & Nkume & & \\
\hline & & + & $\begin{array}{l}\text { dja N kume } \\
\text { dja }\end{array}$ & & \\
\hline \multirow[t]{4}{*}{+} & & & $\begin{array}{l}\text { dja } N \\
\text { kumeba dja }\end{array}$ & & \\
\hline & + & & N kumedu & + & \\
\hline & & + & $\begin{array}{l}\underset{\operatorname{dja} N}{\text { kumedu dja }}\end{array}$ & + & \\
\hline & & & N kumeda & & + \\
\hline
\end{tabular}

Interpretacja wszystkich przykładów potwierdza raz jeszcze, że wartość semantyczna kreolskiej syntagmy werbalnej jest konfiguracją znaczeń poszczególnych jej komponentów, czyli konfiguracją wartości reprezentowanych przez wykładniki wszystkich kategorii werbalnych, wśród których prymarną rolę odgrywa kategoria aspektu. Zdaniem Veigi (1995: 205) kombinacja wszystkich wykładników może doprowadzić do utworzenia nawet 34 odmiennych form werbalnych.

\section{Uwagi końcowe}

Wszystkie języki kreolskie wypracowały podobne strategie dla wyrażania gramatycznych kategorii werbalnych, kodując wartości aspektowe, modalne i czasowe w morfemach gramatycznych, które mogą występować w pozycji prewerbalnej lub postwerbalnej. Niektóre z nich występują jako morfemy luźne, inne współtworzą syntetyczną formę werbalną, tak jak to zaprezentowaliśmy na przykładzie kreola $\mathrm{z}$ wyspy Santiago.

Przedstawiony przez nas mechanizm funkcjonowania wykładników kategorii werbalnych w języku santiaguense nie oznacza, że wszystkie kreole realizują ten sam schemat. Na przykład w badanych przez Dereka Bickertona (1981) angielskich językach kreolskich występowały zaledwie trzy wykładniki - wszystkie w pozycji prewerbalnej: wykładnik czasu $(\mathrm{T})+$ wykładnik trybu $(\mathrm{M})$ + wykładnik aspektu (A) + podstawowa forma werbalna. Różnice pomiędzy poszczególnymi kreolami polegają na liczbie wykładników, jakimi dysponują, oraz na miejscu tych wykładników $\mathrm{w}$ formie werbalnej.

W kreolach z Górnej Gwinei wykładniki trybu i aspektu występują w pozycji prewerbalnej, natomiast wykładnik czasu zajmuje pozycję postwerbalną (tak jak w santiaguense). Gdyby jednak porównać poszczególne kreole z tej grupy, można by 
zauważyć pewne dalsze różnice. Na przykład w języku santiaguense wykładnik -ba współtworzy syntetyczną formę werbalną ( $N$ kantaba), w kreolu guineense funkcjonuje jako morfem luźny ( $N$ kanta $b a$ ).

Biorąc pod uwagę układ wykładników kategorii czasu, trybu i aspektu w syntagmie werbalnej języka santiaguense, najstarszej odmiany kreola z Górnej Gwinei, możemy stwierdzić, że różni się on od opisanego przez Bickertona układu, który przeszedł do historii badań nad językami kreolskimi jako system TMA. Zaprezentowane w niniejszej pracy przykłady pokazują, że kreol z wyspy Santiago dzieli z innymi językami kreolskimi te same mechanizmy tworzenia form werbalnych, prezentując jednak układ wykładników czasu, trybu i aspektu, który możnaby określić mianem systemu MAT.

\section{Literatura}

Bickerton D., 1981, The Roots of Language, Ann Arbor.

Bickerton D., 1984, The Language Bioprogram Hypothesis, „Behavioral and Brain Sciences" 7, nr 2, s. 173-221, [on-line:] https://doi.org/10.1017/So140525Xooo44149.

Couto H.H. do, 1996, Introdução ao estudo das línguas crioulas e pidgins, Brasília.

Hagemeijer T., Alexandre N., 2012, Os crioulos da Alta Guiné e do Golfo da Guiné: uma comparação sintáctica, „PAPIA. Revista Brasileira de Estudos do Contato Linguistico" 22, s. 233-251.

Hlibowicka-Węglarz B., 1998, Processos de expressão do aspecto na língua portuguesa. Algumas observaçoes de carácter contrastivo polaco-português, Lublin.

Hlibowicka-WęGlarz B., 2013, Portugalskie języki kreolskie w Afryce, Lublin.

HLibowickA-WęGLARz B., 2018, „O cudownych formacjach”, czyli rzecz o językach kreolskich, ,LingVaria” nr 1 (25), s. 21-36, [on-line:] https://doi.org/10.12797/LV.13.2017.25.02.

LANG J., 2018, Gramática do crioulo da ilha de Santiago (Cabo Verde), [on-line:] https://opus 4.kobv.de.PrimeiroCapCAtuloIncluCAdo (dostęp: 15 IX 2019).

Pereira D., 2006, Crioulos de base portuguesa, Lisboa.

Quint N., 2005, Línguas crioulas num Contexto de Globalização. O caboverdiano: uma língua mundial, „PAPIA. Revista Brasileira de Estudos do Contato Linguístico” 15, s. 1-13. VeIga M., 1995, Introdução à gramática do crioulo de Cabo Verde, Praia.

VeIga M., 2002, O caboverdiano em 45 lições. Estudo sociolinguístico e gramatical, Praia.

\section{The Structure of Creole Verb Forms Summary}

The study examines the morphosyntactic features of a creole verb system, as well as the principles of its functioning. It focuses on the markers of tense, mood and aspect (the TMA system) that, due to the uniqueness of the system's functioning, have been investigated for many decades. The examples quoted in the paper come from Santiaguense, the oldest form of Cape Verde Creole that developed in the $16^{\text {th }}$ century on the lexical basis of Portuguese. 